\title{
Caso Clínico-Radiológico Adulto
}

\author{
CLAUDIA AZÓCAR B.* y EDUARDO SABBAGH P.**
}

Paciente de 42 años con antecedentes de tabaquismo de 15 paquetes/año, síndrome depresivo y anorexia. Presenta cuadro de un mes de evolución, caracterizado por dolor torácico izquierdo asociado a aumento de volumen en el tercio superior de la cara anterior del hemitórax ipsilateral. A lo anterior se asocia baja de peso de $5 \mathrm{~kg}$. Al examen fisico destaca una paciente

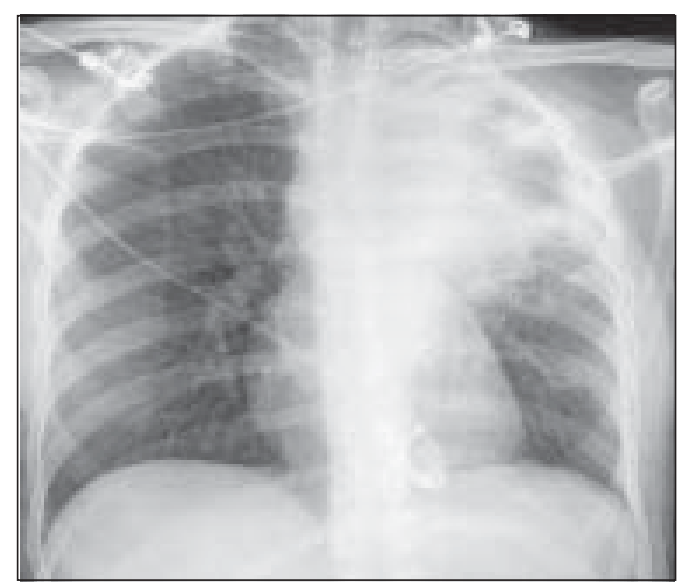

Figura 1. Rx de tórax en proyección póstero-anterior.

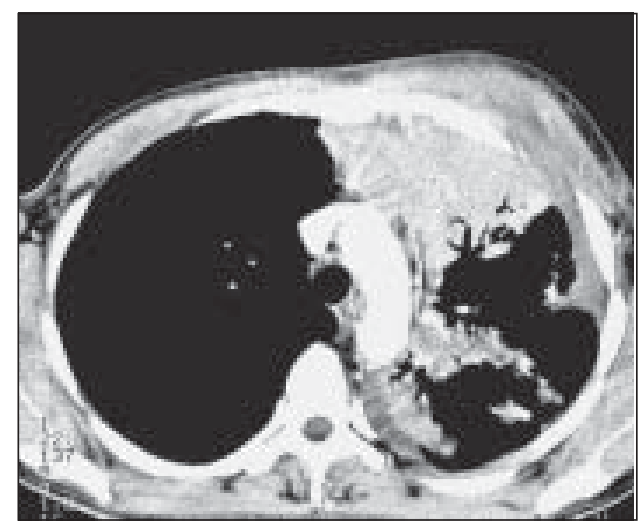

Figura 3. TAC de tórax (técnica de tejidos blandos). enflaquecida, pálida, con un aumento de volumen en la cara anterior del hemitórax izquierdo. Entre los exámenes de laboratorio practicados el hemograma detectó una anemia hipocroma, (concentración de hemoglobina $=8,7 \mathrm{~g} / \mathrm{dl}$, hematocrito $=31 \%$ y VHS $=116 \mathrm{~mm}$ en 1 hora), leucocitosis $\left(17.700 / \mathrm{mm}^{3}\right)$, VIH fue negativo. Detectándose desnutrición proteica (albuminemia de $2,9 \mathrm{~g} / \mathrm{dl}$ ).

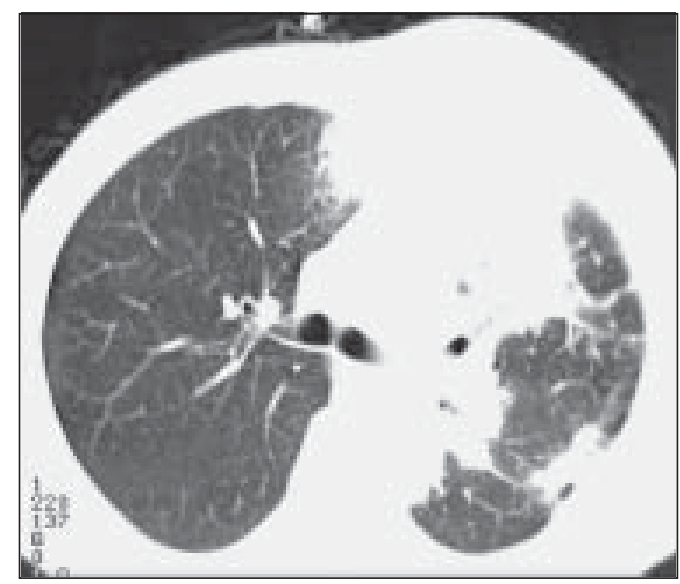

Figura 2. Tomografía axial computada (TAC) de tórax (técnica de parénquima).

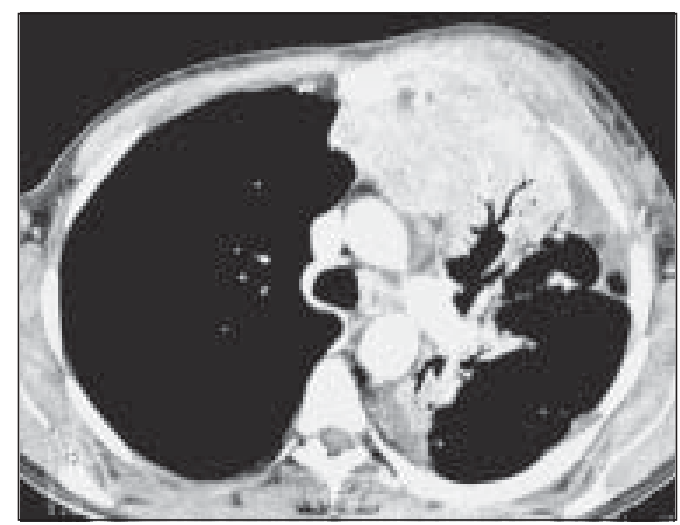

Figura 4. TAC de tórax (técnica de tejidos blandos).

\section{Comente las imágenes de las Figuras 1 a 4 y proponga un diagnóstico diferencial.}

\footnotetext{
* Becaria Enfermedades Respiratorias, Facultad de Medicina, Universidad de Chile ** Servicio de Radiología, Instituto Nacional del Tórax.
} 


\section{Descripción}

La radiografía simple de tórax (Figura 1) y la tomografía computada con técnica de parénquima (Figura 2), demuestran un extenso proceso condensante del pulmón que compromete principalmente al segmento anterior y parcialmente al lingular y ápico-posterior del lóbulo superior izquierdo, presentando además broncograma aéreo. En los cortes de tomografía con técnica de tejidos blandos (Figuras 3 y 4), se aprecia compromiso además de la pleura, con discreto derrame, que se extiende a la pared tanto mediastínica, como anterior, en donde se aprecia extenso compromiso parietal con engrosamiento de tejidos blandos y colecciones de líquido entre los planos musculares, lo que coincide con hallazgos del examen físico.

\section{Comentario y diagnóstico diferencial}

El estudio radiológico demuestra un proceso parenquimatoso condensante con compromiso pleuro-parietal, con bronquios permeables. El diagnóstico diferencial debe considerar tanto lesiones neoplásicas como procesos infecciosos. Dentro de las neoplasias habría que incluir el cáncer broncogénico, dentro de los cuales cualquier variedad puede comprometer la pared torácica, especialmente la variedad de células escamosas, aunque la presencia de broncograma aéreo es atípica en este tipo de neoplasias a excepción del carcinoma bronquíolo-alveolar, el cual no compromete la pared torácica. Otras neoplasias con estas características y que sí pueden presentar broncograma son los procesos linfoproliferativos, en los cuales suele haber un compromiso ganglionar importante y predominante, especialmente en el linfoma de Hodgkin, elemento que en este paciente es irrelevante.

Por otra parte se deben considerar los procesos infecciosos, especialmente granulomatosos, dentro de los cuales en nuestro medio destaca la TBC, llamando la atención en este paciente la ausencia de necrosis en el parénquima y la ausencia de retracción que suele caracterizar a estos procesos. Otras granulomatosis por hongos son muy poco frecuentes en nuestro medio. La Nocardia es otro agente infeccioso que puede producir este tipo de lesiones. Finalmente el Actinomyces israelii característicamente produce focos de neumonía del espacio aéreo distal, como focos de condensación parenquimatosa, que pueden presentar broncogramas aéreos, con o sin necrosis y que además frecuentemente comprometen la pleura y pueden extenderse a la pared torácica, incluso con fístulas cutáneas, las que en el examen físico muestra focos supurados con aspecto de "gránulos de azufre". Esto último no era visible en nuestro paciente.

La biopsia de la lesión de la pared torácica demostró un proceso inflamatorio agudo y crónico focalmente supurado, observándose microorganismos con caracteres de actinomyces.

\section{Diagnóstico:}

Actinomicosis pulmonar con compromiso pleural y de la pared torácica.

\section{Evolución}

Luego de la confirmación del diagnóstico de actinomicosis pulmonar, se inició tratamiento con penicilina sódica ev 16 megaunidades diarias durante 25 días, ulteriormente se indicó amoxicilina $1 \mathrm{~g}$. cada $8 \mathrm{~h}$ por vía oral.

La paciente evolucionó con derrame pericárdico que se puncionó y drenó, resultando ser un líquido con características de exudado. El examen citológico para células neoplásicas y las baciloscopías del derrame pericárdico resultaron negativas. El estudio inmunológico también fue negativo. Posteriormente se reinició el tratamiento con penicilina sódica por sospecha de compromiso pericárdico por actinomicosis. La evolución clínica, radiológica y de laboratorio fue favorable, comprobándose regresión del derrame pericárdico, de la masa pulmonar y del compromiso de la pared torácica. Ha completado 8 semanas con tratamiento antibiótico ev. y continuará con tratamiento ambulatorio con amoxicilina, hasta completar un tota de 12 meses de tratamiento..

\section{Bibliografía}

1.- MAKARYUS A N. A rare case of Actinomyces israelii presenting as pericarditis in a 75-year-old man. Cardiol Rev 2005; 13: 125-7.

2.- SHINAGAWA N. Pulmonary actinomycosis followed by pericarditis and intractable pleuritis. Intern Med 2002, 41: 319-22.

3.- MABEZA G F. Pulmonary Actinomycosis. Eur Respir J 2003; 21: 545-51.

4.- SMEGO R A. Actinomycosis. Clin Infect Dis 1998; 26: 1255-61.

5.- TAE SUNG KIM. Thoracic Actinomycosis: CT Features with Histopathologic Correlation. AJR 2006; 186: 225-31.

6.- Bakhtawar I. Utility of Wang Needle Aspiration in the Diagnosis of Actinomycosis. Chest 2001; 119; 1966-8. 